\title{
Human and policy dimensions of soundscape ecology
}

\author{
Jordan W. Smith ${ }^{\mathrm{a}, *}$, Bryan C. Pijanowski ${ }^{\mathrm{b}}$ \\ ${ }^{a}$ Center for Geospatial Analytics, North Carolina State University, Raleigh, NC 27695, United States \\ ${ }^{\mathrm{b}}$ Human-Environment Modeling and Analysis Laboratory, Purdue University, West Lafayette, IN 47907, United States
}

\section{A R T I C L E I N F O}

\section{Article history:}

Received 11 June 2013

Received in revised form 21 May 2014

Accepted 29 May 2014

Available online

\section{Keywords:}

Coupled natural and human systems

Feedback loops

Bioacoustics

Psychoacoustics

Noise and health

\begin{abstract}
A B S T R A C T
Soundscape ecology is an emergent and potentially transformative scientific discipline. However, the majority of research within the field has been conducted by natural scientists focused on quantifying the characteristics and dynamics of soundscapes and examining their effect on non-human biota. A more holistic approach to the science and management of soundscapes requires full integration with the social and policy sciences. To facilitate the development of this integration, we propose an integrative human and policy dimensions of soundscape ecology framework that conceptualizes the complex and dynamic relationships between humans and their acoustic environments. The framework is grounded in four distinct disciplines - health, psychology, economics and anthropology - that have used different methodologies and metrics to focus on certain aspects of human-soundscape interactions. We provide a review of previous empirical research within each of these fields. Along the way, we identify unexplored avenues of discipline-specific research that can further the field of soundscape ecology. The human and policy dimensions of soundscape ecology framework provide the logic and structure upon which an interdisciplinary body of scholarship can be built in the future. We conclude by utilizing our review and integrative framework to propose specific focused soundscape policy and management recommendations. We argue the anthropogenic dominance of soundscapes can be mitigated through more proactive, integrative and holistic soundscape policies and management practices.
\end{abstract}

(c) 2014 Elsevier Ltd. All rights reserved.

\section{Introduction}

Soundscape ecology is an emergent and potentially transformative scientific discipline (Servick, 2014). The field originated in the 1970 s, grounded in the hypothesis that "every location on earth has a unique acoustical bio-spectrum that provides information on the dynamics of ecosystems in that place" (Krause, 1987, p. 15). Individual non-human species were suggested to occupy an aural niche within a specific geographic location. This hypothesis was a dramatic departure from previous bioacoustics research focused solely on single-animal vocalizations given it suggested the acoustic properties of individual locations play an integral role in ecosystem structure and functioning (Farina, 2014a). By collecting acoustic recordings of specific locations over time, soundscape ecologists believed they could better understand how certain changes in anthropogenic, biological and geophysical sounds affect the health of an ecosystem (e.g., biological diversity, provisioning of ecosystem

\footnotetext{
* Corresponding author. Tel.: +1 435830 6294; fax: +1 9195153439 .

E-mail address: jordan_smith@ncsu.edu (J.W. Smith).
}

services, etc.). Similar to the field's theoretical innovation, the methods and metrics proposed and utilized by soundscape ecologists differed dramatically from the use of traditional ecological indicators, such as population counts for key species.

The theories and methodologies employed by soundscape ecologists have expanded greatly over the past several years with improvements to recording hardware, processing software and statistical models (Pijanowski et al., 2011b). However, to date, the vast majority of soundscape ecology research has been conducted by natural scientists and has remained focused on quantifying how the acoustic dynamics of a place, such as the presence/absence and amplitude of anthropogenic noise, affect non-human biota (e.g., Kuehne et al., 2013; Proppe et al., 2013; Tucker et al., 2014). While this research is essential to advancing our knowledge of bioacoutics, a more comprehensive understanding of soundscape ecology can be built through alternative perspectives offered by other fields including spatial ecology, psychology and the humanities (Pijanowski et al., 2011a). For example, spatial ecology can provide insight as to how geophysical spatial patterns such as topography and vegetation influence the composition and dynamics of a location's soundscape (e.g., Pekin et al., 2012). 


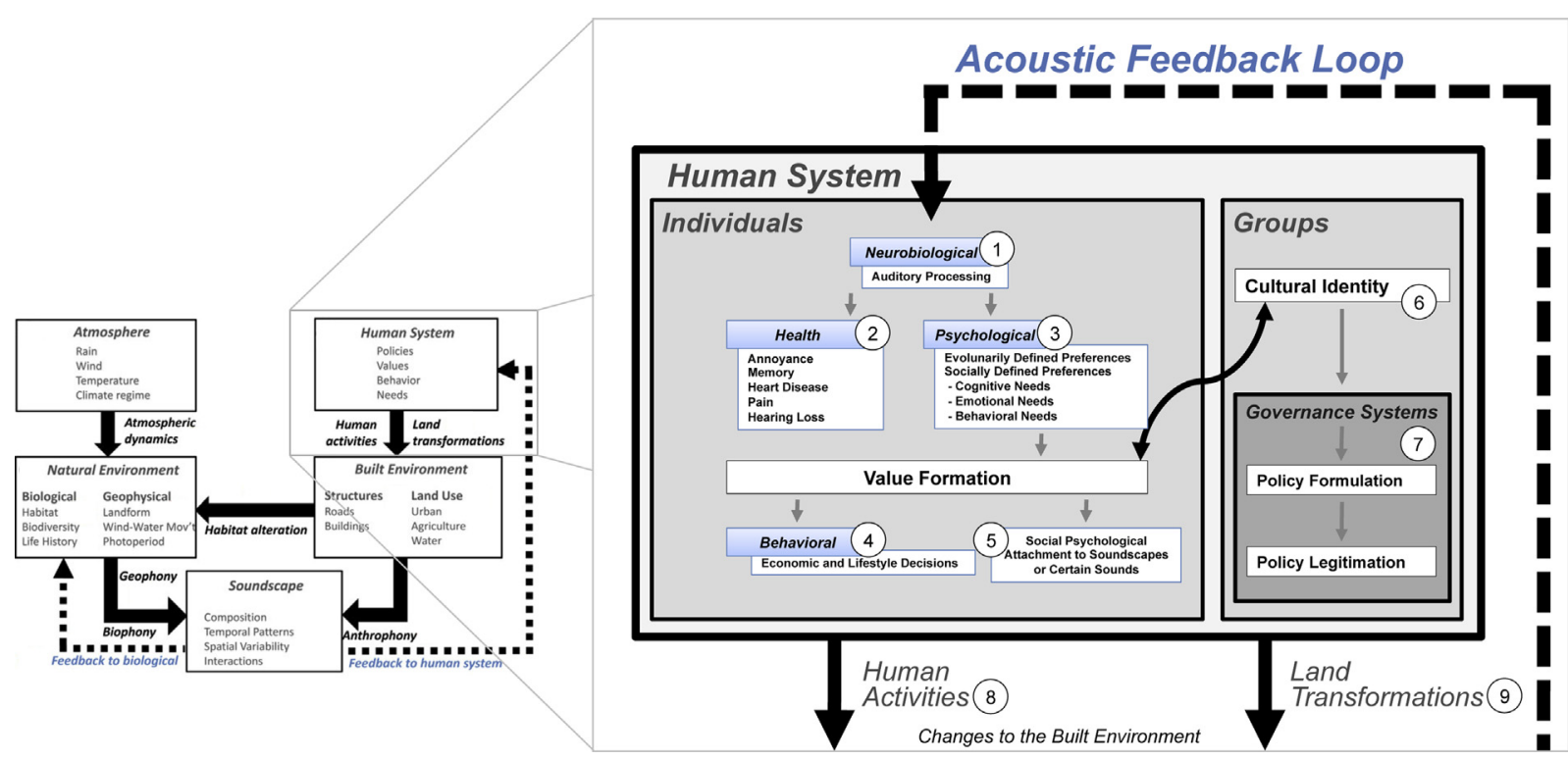

Fig. 1. The human and policy dimensions of soundscape ecology framework.

Similarly, psychology can be employed to better understand how humans perceive and respond to a place's aural dimensions (e.g., Guastavino and Katz, 2004).

Recognizing the need for more integrative approaches to soundscape ecology, Pijanowski and his colleagues (2011a) developed a model in which soundscapes were conceptualized as the product of coupled natural and human systems (Fig. 1). The intent was to provide an organizing framework for understanding the factors shaping the characteristics and dynamics of soundscapes. The framework is grounded in the principles of land change science, which acknowledge that landscapes are temporally and spatially variable systems perturbed by both natural and anthropogenic drivers (Turner et al., 2007). Collectively, these driving factors shape the composition and dynamics of a specific geographic locations' acoustic environment. For example, atmospheric processes such as rain, thunder and wind movement interact with the biogeophysical properties of a landscape (topography, land cover, etc.) to produce sounds that vary across time and space. The properties and dynamics of soundscapes, in turn, feedback into and shape both natural and human systems. For example, the acoustic characteristics of a landscape can have a significant effect on animal species' ability to perceive biologically important sounds (e.g., mating calls) and consequently affect their own vocalization patterns (Barber et al., 2010; Laiolo, 2010). Similarly, humans are also functionally connected to the acoustic characteristics of landscapes. Psychological attachments are formed to specific places because, in part, the sounds heard in those places contribute to unique and memorable experiences (Morgan, 2010; Ryden, 1993). Indeed, soundscapes are creations of both natural and human systems, but they also have important, but often poorly understood, feedbacks into these systems (Pijanowski et al., 2011a).

Pijanowski and his colleagues emphasized their framework was not exhaustive, noting each component of the framework (atmospheric processes, biogeophysical properties, human systems and the built environment) were in and of themselves complex systems with many research questions yet to be explored. The role of sound within each of these systems has been examined to varying degrees. Our understanding of the interactions between sound and biogeophysical processes continues to grow rapidly (Fletcher, 2007). However, research focused on the interaction between sound and human systems remains fragmented among different disciplines, each of which utilizes its own epistemologies, theories and methodologies (Dumyahn and Pijanowski, 2011a,b; Farina, 2014b).

The objectives of this paper are threefold: First, to present an integrative human and policy dimensions of soundscape ecology framework that provides the logic and structure upon which an interdisciplinary body of scholarship can be built in the future. Second, to review the literature from four distinct disciplines health, psychology, economics and anthropology - that have either directly or indirectly investigated how soundscapes affect human psychology, behavior or governance systems. Throughout our review, we highlight unexplored avenues for future research. By distilling large and often disparate bodies of the literature and previous findings, the integrative framework and disciplinary reviews allow us to achieve our third objective of developing focused and scientifically informed soundscape policy and management recommendations.

\section{Soundscapes and soundscape ecology: a brief introduction to definitions and concepts}

Because the breadth of soundscape research is so broad, being explored independently by different disciplines, there are numerous ways to define what a soundscape is. Most definitions agree on two points: First, the term refers to the totality of a sonic environment and second, that the aggregate composition of sounds is tied to a specific place. The Oxford dictionary is most succinct on these two points, defining a soundscape as "the sounds heard in a particular location, considered as a whole." Similarities are apparent in soundscape management policies, such as those that exist in the UK which describe soundscapes as "the totality of all sounds within a location with an emphasis on the relationship between [an] individual's or society's perception of, understanding of, and interaction with the sonic environment" (2009, p. 7). More recent conceptualizations have expanded upon the anthropocentric focus of these definitions to encompass non-human ecological processes as well. Specifically, Pijanowski et al. (2011b) define the term as all sounds - those produced from human activity, those created by biological sources and those generated as a result of geophysical processes - emanating from a given landscape. Building upon early work within the field of soundscape ecology (e.g., Krause, 1987; Schafer, 1977; Truax, 1999), Pijanowski and his 
colleagues suggest that all soundscapes are comprised of three components: (1) anthrophony, the sounds deriving from individual human activities and the built environment; (2) biophony, the sounds originating from biological organisms; and (3) geophony, naturally occurring geophysical sounds (e.g., rain, wind, etc.). Each of these three compositional inputs varies across time and space, interact with one another and result in dynamic soundscapes within a specific geographical setting.

We adopt the definition of a soundscape as the perception of all sounds - those produced from human activity, those created by biological sources and those generated as a result of geophysical processes - emanating from a given landscape. This definition is consistent with the recently developed International Standard ISO/ FDIS 12913-1, which distinguishes between an acoustic environment, comprised solely of the physical presence of sound itself, and soundscapes, which involve both sound and human perception (International Standards Organization, 2013). A definition that acknowledges both the natural and human components of a soundscape is essential for effective cross-disciplinary communication (Brown et al., 2011).

\section{An integrative framework of the human and policy dimensions of soundscape ecology}

The human and policy dimensions of soundscape ecology framework details only one sub-component of the coupled natural and human systems model developed by Pijanowski and his colleagues (Fig. 1; 2011a). The coupled natural and human systems model, which has been foundational in the formation and growth of soundscape ecology (Farina, 2014a), is built upon the idea that continuous human interaction with the natural environment has resulted in complex organizational, spatial and temporal coupled systems (Liu et al., 2007). We begin by presenting the framework and describing its individual components and how they draw upon a variety of different disciplines. Subsequently, we present the detailed discipline-specific reviews that were utilized to construct the framework. We conclude with specific policy and management guidelines that can be derived form the framework and the research from which it was constructed.

First, the acoustic properties of soundscapes enter the human system at the individual level through auditory processing (Fig. 1, Label 1; Werner, 2012). Individuals reconstruct scenes based upon their ability to identify distinct auditory objects, such as frog calls or motor vehicles (Litovsky, 2012). Meaning is ascribed to auditory objects based upon what Russell dubbed 'affective quality' (e.g., pleasant/disturbing, relaxing/alarming) (Russell, 2003). Once individuals ascribe meaning to auditory objects, they incorporate assessments of the landscape's esthetic properties and subsequently form an integrative assessment of the visual and auditory environment (Lewis et al., 2012). The psychological process of ascribing meaning to certain sounds leads to basic physiological responses, such as changes in blood pressure levels and hormone levels related to anxiety (Label 2). This causal chain between psychological and physiological process follows the allostasis theory, which suggests the brain anticipates environmental stimuli and prepares the body for action (McEwen, 2000). Rapid physiological responses can eventually lead to long-term undesirable health outcomes such as reduced cognitive processing abilities and an increased probability of experiencing a heart attack (McEwen and Seeman, 1999).

Continuing with the psychological responses to sound (Label 3), "the perception of the soundscape is inherently personal and affected by what listeners, each with [their own] unique sets of experiences and preferences, brings to the listening situation" (Jennings and Cain, 2013, p. 295). Past research suggests individuals prefer landscapes based upon both the evolutionary advantages they provide as well as their ability to meet cognitive, behavioral and emotional needs. Positive meanings and preferences are given to landscapes that are non-threatening, an evolutionarily defined predisposition shown to be consistent across cultures (Kaplan and Kaplan, 1989; Falk and Balling, 2010). The question of whether evolutionarily defined landscape preferences are partially driven by soundscape characteristics and dynamics, however, remains to be explored. Evidence is available that suggests individuals prefer landscapes and soundscapes that meet cognitive needs (e.g., the need to maintain a personal sense of identity that is tied to a specific geographic space or specific sounds), behavioral needs (e.g., the need to hear certain sounds to engage in specific behaviors) and emotional needs and desires (e.g., the desire to experience solitude in quiet locations) (e.g., Bradley and Lang, 2000; Hvenegaard, 2002; Stewart, 1992).

Preferences and values toward specific auditory objects are believed to drive personal behaviors (Label 4; Stern, 2000). For example, if an individual values birdsong because it allows them to test their skills as a bird watcher, they are more likely to travel further to reach areas rich in certain avian sounds (Ruddell and Gramann, 1994). Similarly, individuals who value a home environment where they cannot hear traffic will be more likely to pay more for a home in a quiet neighborhood. The connection between sound and individual economic decisions, when extrapolated to entire populations, implies that certain sounds can, and actually do, have significant impacts on large economic systems such regional housing markets.

Valuing certain soundscapes or individual sounds may, over time, lead to relatively enduring psychological attachments to those soundscapes or sounds (Label 5). An empirical linkage between acoustic preferences and the establishment of an enduring sense of place has yet to be fully explored. Existing tangential evidence suggests sound is a key factor shaping the formation of individuals' self-identity. For example, certain types of recreationists such as birdwatchers and backcountry hikers develop unique personal identities because of their ability to experience specific types of sounds or soundscapes in recreational areas (Hvenegaard, 2002; Scott et al., 2005).

The relationship between soundscapes and human psychology is not just manifested through the behaviors of individuals. Rather, it is relatively enduring and can play a fundamental role in how groups, and even entire cultures, develop (Label 6; Morgan, 2010; Samuels et al., 2010). The values individuals ascribe to landscapes and their acoustic characteristics are known to be socially constructed by groups and societies as their cultures continue to adapt and evolve (Blackmore, 2000; Richerson and Boyd, 2004). The ascription of particular meanings to local sounds can shape group identity formation; a prime example of this is the welldocumented songscapes of Native American tribes in the southwestern US (Ferguson et al., 2009). These Native American songscapes are culturally meaningful songs using lyrics describing specific geographic locations and the seasonal migration patterns of individual tribes. Individual psychological processes and the social contexts in which they occur are codependent and evolve together over time (Richerson and Boyd, 2004).

Socially defined values toward soundscapes and specific sounds are formalized and legitimized through public policy and management systems (Label 7). Public policy and management issues related to soundscapes remain largely underexplored (Weber, 2013). Most commonly, public policies focus on noise sources such as heavily used highways and airports, which pose a clear public nuisance. Acoustic environments are reduced to a fundamental unit, typically sound pressure levels, which can be easily measured and enforced.

The final stage of sound's movement through the human system involves individual (Label 8 ) and collective behaviors 
(Label 9) that shape the acoustic properties of a particular soundscape (Label 9). It is at this juncture that the coupled system reaches closure and the dynamics of acoustic feedback properties become drivers of soundscape change.

Collectively, the human and policy dimensions of soundscapes are vast and have been tangentially touched upon by a wide variety of disciplines ranging from neurobiology to anthropology and social psychology. These diverse disciplines offer complimentary bodies of evidence for how human systems are affected by the acoustic properties of their environments. In the sections to follow, we present four detailed discipline-specific reviews that were utilized to construct the framework. The specific disciplines covered - health, psychology, economics and anthropology were selected because each has a substantial body of theory and empirical evidence related to human-soundscape interactions. Future reviews from other fields can incorporate their disciplinespecific knowledge into the human and policy dimensions of soundscape ecology framework and create a more integrative body of knowledge dedicated to understanding the dynamic human dimensions of soundscapes.

In each of the four reviews below we point out disciplinary research needs that, if addressed, would lead to a more integrated understanding of the human and policy dimensions of soundscape ecology. We conclude with a detailed review of current soundscape-related policies and regulations. We describe how existing governance mechanisms are inadequate and ill-suited to successfully conserve the diminishing availability of natural soundscapes on a global scale.

\subsection{Individual and public health}

\subsubsection{Existing knowledge}

Soundscapes affect human health in a variety of ways (Fig. 1, Label 2). Known effects are multi-phasic, first involving short-term physiological responses to certain sounds. Short-term responses are mediated by the autonomic nervous system and include changes in blood pressure, heart rate, depth and rate of respiration, pupil size, skin conductance levels, muscle tension, endocrine outputs and vascular constriction (Stansfeld, 1992). Undesirable physiological activations, most notably increases in heart rate, blood pressure and vasoconstriction, contribute to numerous longterm health impacts that are wide-ranging and highly variable in severity. Known effects range from subjective appraisals of annoyance (Miedema and Oudshoorn, 2001; Miedema, 2007) to sleep deprivation (Muzet, 2007), cognitive impairment (Stansfeld et al., 2005), heart disease (Babisch, 2008) and of course hearing loss (Burns, 1973; Kryter, 1985). The majority of previous research on human health impacts of sound has focused on specific noise sources and environments such as airports, highways and industrial worksites, which pose especially high exposure risks. Despite the highly variable nature of noise sources and their health consequences, nearly all previous research has been framed within a simple dose-response model whereby exposure to sounds at increasingly unpleasant amplitudes and over increasingly extended periods of time leads to progressively severe health impacts (Sharp, 2010).

Several review papers provide detailed accounts of previous research focused on the human health impacts of noise (Moudon, 2009; Stansfeld and Matheson, 2003; Stansfeld et al., 2000a, $2000 \mathrm{~b})$. Collectively there is little evidence for adverse health outcomes at exposures less than $30 \mathrm{~dB}(\mathrm{~A})$. Modest adverse effects begin to emerge around $40 \mathrm{~dB}(\mathrm{~A})$ where large proportions of subjects in clinical studies and field-based experiments report high levels of annoyance (Miedema, 2007). At levels between $40 \mathrm{~dB}(\mathrm{~A})$ and $55 \mathrm{~dB}(\mathrm{~A})$, sustained concentration and memory are impaired (Stansfeld et al., 2005). The most severe health impacts have been found in repeated exposure to sounds over $55 \mathrm{~dB}(\mathrm{~A})$. For example, Van Kempen et al. (2002) found the risk of ischemic heart disease increased by $1.09 \%$ for every $5 \mathrm{~dB}(\mathrm{~A})$ increase in daytime noise exposure between 50 and $70 \mathrm{~dB}(\mathrm{~A})$. To put this risk in context, Babisch (2008) conducted a meta-analysis of 61 noise exposure studies and concluded that daytime exposure levels rarely drop below $50 \mathrm{~dB}(\mathrm{~A})$ in urban areas. Prolonged exposure to noise above $75 \mathrm{~dB}$, typically experienced by individuals living adjacent to highways and airports, is linked to increasingly severe cardiovascular risks such as higher probabilities of suffering a myocardial infarction (Babisch, 2008). At sound pressure levels above 130(dB), individuals experience acute pain and hearing loss.

\subsubsection{Current and future research needs}

There are numerous pressing research needs in the area of sound exposure and human health responses as evidenced by entire academic journals and conferences being devoted to the subject. Here, we focus in on the broad research needs that will become increasingly important given global environmental and social changes such as rapid rates of urbanization.

First, existing knowledge of the human health impacts from noise have been established through rigorous laboratory experiments (Stansfeld et al., 2000a). Now there is a need for established findings to be translated into epidemiological terms measuring population-wide effects (Miedema, 2007; Moudon, 2009). Exposure to unwanted sounds will become an increasingly endemic public health issue as the population densities of urban areas continue to increase. Translating known decrements to human health from established dose-response relationships to population-wide projections of impacts and their associated costs has the potential to increase the willingness of elected officials and public health professionals to make soundscape management polices a higher priority. While the World Health Organization has made valuable progress in this area in Europe (World Health Organization, 2011), coordinated and international epidemiological studies would undoubtedly raise the awareness of soundscapes and their impact on human health. Conflict over noise mitigation policy in the Netherlands is evidence of members of the general public realizing the negative consequences of noise and advocating for polices that promote quieter and healthier communities. During the 2012 legislative session, citizens, local governmental bodies and politicians formed advocacy coalitions alongside public health institutes and non-governmental organizations and successfully lobbied for the parliament to revise pending legislation to include mandatory monitoring and measurement of sound pressure levels near highways (Ministry of Infrastructure and Environment, 2011; Weber, 2013).

Second, a dedicated line of inquiry is needed to understand how desirable soundscape characteristics impact health outcomes. Nearly all previous noise and health studies have adopted a doseresponse relationship where unwanted anthropogenic sounds are the primary independent variable of interest. Very little, if any, research has applied the dose-response model to examine the other two components that define a soundscape - geophony and biophony. Recent epidemiological research has established that the availability of parks, greenways and open spaces lead to improved public health outcomes (Sallis et al., 2012). Future research should attempt to disaggregate the characteristics and attributes of more natural landscapes and their effects on human health. The hypotheses that exposure to sound from geophysical and biological sources is related to positive human health responses warrants future exploration. These propositions would benefit from a careful examination through controlled laboratory experiments, field-based case studies and analysis of secondary data. Inverting the dose-response model to examine potentially beneficial responses to geophysical and biological sounds may also 
yield valuable and broader insights for urban and landscape planning processes and polices. Documented evidence for human health benefits associated with experiencing natural sounds would increase the impetus to maintain or improve the biological diversity and ecological integrity of natural areas threatened with continued fragmentation.

While the benefits of future research into the intersection between soundscapes and human health are wide ranging, there will still be considerable barriers in translating scientific findings into policy change. Environmental policies in general, suffer from decisions being made out of the need to avoid overt and welldocumented threats to human health and safety as opposed to the need to improve human well being (Braybrooke and Lindblom, 1963). There is growing interest among landscape and environmental planners to develop novel methods of documenting the positive health benefits of pleasing and desirable soundscapes. For example, Jennings and Cain (2013) recently proposed a novel framework for gauging the objective qualities of urban soundscapes (i.e., composition and sound pressure levels), identifying the factors affecting whether these might be perceived as positive and developing specific strategies for conveying those positive aspects to diverse sets of individuals such as urban planners. The translation of soundscape science into policy change will undoubtedly require more creative work along these lines.

\subsection{Psychology: evolutionary defined preferences}

\subsubsection{Existing knowledge}

Humans ascribe meaning to natural landscapes and their sounds (Fig. 1, Label 3). The ascription of these meanings can be either implicit and unconscious or explicit and socially constructed. Implicit and unconscious meanings, those that appear to be most directly related to human nature, are biologically determined and have principally been examined within the field of evolutionary psychology. The basic thesis is that cognitive functioning is a product of natural selection. Ancestral humans more capable of seeking out safe locations within a landscape were more likely to pass on their genes to subsequent generations. Consequently, modern humans are genetically hard-wired to prefer natural landscapes and soundscapes that minimize physical risks.

Historical as well as cross-cultural evidence supports the theory that landscape preferences are biologically determined. Appleton (1975) draws upon historical evidence such as landscape paintings from diverse origins to suggest humans have a natural affinity toward savannah-like landscapes (i.e., large open spaces defined by low shrubs and edges defined by taller trees). These landscapes are believed to provide individuals with both the opportunity to detect potential hazards as well as places to hide and escape. Kaplan and Kaplan (1989) suggest preferences for landscapes offering both prospect and refuge makes sense when described in terms of evolutionary psychology because these types of landscapes minimize risks associated with acquiring information and resources (e.g., food and prey). Recent empirical work across a diversity of cultural contexts such as Africa (Falk and Balling, 2010), Asia (Orians and Heerwagen, 1992; Orians, 1980), Europe (García-Llorente et al., 2012; Tempesta, 2010) and North America (Balling and Falk, 1982) supports the theory that landscape preferences are biologically determined.

\subsubsection{Current and future research needs}

The literature on the evolutionary psychology of landscape preferences implicitly suggests the seemingly universal "human nature" of landscape choice is defined by how we take in, and cognitively process information visually (Kaplan, 1992). The biological underpinnings of soundscapes remain unexplored
(Wallin et al., 2000). A logical extension of the evolutionary psychology thesis would be to suggest savanna-like landscapes also offer acoustic advantages over other landscape types such as rain forests, coniferous forests, deciduous forests and deserts. Dense forested landscapes dampen sounds, making it difficult to discern sounds associated with known threats. Conversely, the acoustic properties of deserts allow sound to travel easily across the landscape, resulting in increased exposure and risk. Only savannah-type landscapes offer the acoustic characteristics whereby potential prey located in the open can be detected more easily, not only visibly, but also sonically. Simultaneously, acoustic exposure risks are mitigated through the ability to quietly hide in the taller vegetation located along the edges of the open space. The evolutionary development of human psychological preferences is likely to have arisen not only out of our visual perception of natural landscapes, but through our cognitive auditory processing as well.

\subsection{Human psychology: socially defined preferences}

\subsubsection{Existing knowledge}

The previous section does not imply landscape and soundscape preferences are solely the product of human sociobiology, a large body of literature from the field of environmental psychology reveals a great degree of preference heterogeneity within individual populations. These theoretical perspectives are not contradictory. As the eminent sociobiologist E.O. Wilson notes, "particularities in decision making distinguish one human being from another. But the rules followed [in decision making] are tight enough to produce a broad overlap in the decisions taken by all individuals and hence [yield] a convergence powerful enough to be labeled human nature" (2004, p. 67). The field most capable of understanding preference heterogeneity within individual populations is environmental psychology.

A variety of concepts such as place attachment (Tuan, 1974), sense of place (Jorgensen and Stedman, 2001) and place meanings (Smith et al., 2011) have been utilized and refined through psychometric research, to gain a finely tuned understanding of why and how individuals become psychologically attached to various landscapes. Psychological connections to particular natural landscapes arise because those landscapes serve distinct cognitive, behavioral and emotional needs.

3.3.1.1. Cognitive and behavioral needs. Cognitive needs refer to the ability of natural landscapes to shape individuals' personal identities (Proshansky et al., 1983). Self identity, individuals' personal appraisals of who they are in reference to others, is believed to be the product of both social relationships (Breakwell, 1992) and relationships to specific geographic spaces (Ittelson et al., 1976). Recent research also suggests natural landscapes play a functional cognitive role in shaping larger social identities, such as those individuals ascribe to their family and their community (Davenport and Anderson, 2005; Smith et al., 2011). Empirical research within this area has primarily focused on understanding how individuals' place identity shapes their preferences for how natural landscapes are managed. This line of research has yet to disaggregate the acoustic and non-acoustic properties leading to individuals becoming attached to certain natural landscapes. Tangential evidence suggests natural sounds are key factors shaping individuals' ability to identify with specific geographic locations. Certain types of recreationists, such as birdwatchers and backcountry hikers, develop unique personal identities because of their ability to experience specific types of sounds or soundscapes. For birdwatchers, the ability to identify certain species solely by their calls is a key indicator of skill and commitment to the activity (Hvenegaard, 2002; Scott et al., 2005). Similarly, a frequently noted motivation for engaging in back country hiking is the ability to 
"escape the sounds of everyday life" (Stewart, 1992). Social norms and identities among certain recreational groups such as snowmobilers, off-highway vehicle users and cross country skiers, are also heavily dependent upon the ability to experience distinct soundscapes (Ruddell and Gramann, 1994).

3.3.1.2. Emotional needs. The acoustic characteristics of natural landscapes also feedback to human psychology through emotional as opposed to cognitive and behavioral channels. The majority of previous research on emotional responses to sound has focused on music (Juslin and Slodoba, 2001). Research on emotional responses to music is driven by obvious applications to film (Cohen, 2001), marketing (Bruner, 1990) and therapy (Bunt and Hoskyns, 2002). The research on emotional responses to music suggest various emotive states such as sadness, fear and happiness arise out of several distinct mechanisms including brain stem reflexes, evaluative conditioning, emotional cognition, visual imagery, episodic memory and musical expectancy (Juslin and Västfjäll, 2008). Each of these mechanisms corresponds to a distinct way that music induces different emotions. For example, brain stem reflex refers to the process whereby distinct acoustic characteristics signal an important or urgent event. Loud, dissonant and fast temporal patterns tend to stimulate arousal and feelings of unpleasantness in listeners (Burt et al., 1995). There is a distinct need to understand how these mechanisms operate in the formation of emotional responses to non-musical stimuli.

Past research on emotional responses to non-musical stimuli has been limited in both quantity and theoretical consistency (De Coensel and Botteldooren, 2006). Early studies utilized semantic differential scales to elicit responses from individuals regarding the extent to which different soundscape recordings were either pleasurable and soothing or annoying and stressful (Bjork, 1985; Gabrielsson and Sjögren, 1979; Kerrick et al., 1969). This research was limited in that it was not capable of eliciting responses to specific acoustic characteristics or sounds within a soundscape recording; it was also limited in the range of emotional responses elicited (typically, only the pleasant/annoying gradient was used). Subsequent research has focused on a broader range of emotional responses such as variations in the ability of soundscapes to evoke soothing or stressful emotional responses (Berglund and Nilsson, 2006; Berglund et al., 2001; Cain et al., 2013; Kawai et al., 2004; Raimbault et al., 2003; Västfjäll et al., 2003; Viollon and Lavandier, 2000). However, this research was still focused on assessing emotional responses to whole soundscape recordings. Only recently have researchers in the field of psychoacoustics begun to disaggregate emotional responses to either specific acoustic characteristics such as frequency (pitch), amplitude (volume) and sound pressure, or distinct types of sounds that originate from human, biological or geophysical sources. The majority of recent research on emotional responses to acoustic characteristics or distinct sounds suggests anthropogenic sounds elicit more annoying and stressful emotions than either biological or geophysical sounds (Axelsson et al., 2010; Dubois et al., 2006; Gustavino, 2006; Nilsson and Berglund, 2006; Viollon and Lavandier, 2000). This only holds true, however, for anthropogenic sounds that could be classified as 'technological' (e.g., traffic). Emotional response to anthropogenic sounds caused by humans themselves can yield both positive (e.g., babies' coos and laughing) and negative (e.g., crying and yelling) affective reactions (Bradley and Lang, 2000)

\subsubsection{Current and future research needs}

Research on emotional responses to soundscapes and specific sounds needs to be expanded in empirical scope. Nearly all previous research has been conducted within the context of industrial sites (e.g., Nilsson, 2007; Västfjäll et al., 2003) or urban areas whose soundscapes tend to be dominated by technological anthropogenic sounds. Research focused on undeveloped areas such as remote areas within natural parks is needed. More empirical focus on the soundscapes in these areas would yield insight into the complex linkages between human psychology and environmental stimuli. A more finely tuned understanding of the extent to which specific and distinct sounds influence human emotions could also provide insight into how to plan for and design socially desirable and emotionally positive built environments (Jennings and Cain, 2013)

\subsection{Economics}

\subsubsection{Existing knowledge}

The field of economics has undoubtedly conducted the most empirical research on how sound impacts human systems. For economists, sound, or more specifically unwanted noise, is an uncompensated external cost affecting individual and market behavior. Noise is a byproduct of either production or consumption activities that adversely affects third parties not directly involved in the transaction (Nelson, 2008). The fundamental role of econometric reasearch has been attempting to generate valid estimates of the uncompensated external costs associated with unwanted sounds. Ideally, the information from valuation studies can inform cost-effective policy design, including choices between different policy options such as regulations, noise pollution taxes and tradable permits.

Valuation of uncompensated external costs is inherently difficult because of the lack of an explicit market for soundscape quality. Outdoor acoustic space is a common-pool resource where there is little or no allocation of use rights for individuals or organizations (Cheung, 1987; Dumyahn and Pijanowski, 2011a). As a result, the valuation of sound has to be accomplished through non-market valuation techniques that can either be classified as revealed preference or stated preference methods.

In revealed preference studies, sound quality is assumed to be a complimentary good consumed in a private market. These markets are almost exclusively urban housing markets whose stock of goods (houses) varies in exposure to unwanted sounds (e.g., airport noise, traffic, etc.). The economist must acquire detailed data on housing market transactions with careful consideration to capture all of the potentially relevant variables known to affect market prices (e.g., structural, accessibility and environmental characteristics aside from sound quality). Long-term average sound exposure measurements must also be compiled across the study area. Regression analyses can subsequently be utilized to unbundle prices and calculate the implicit price for exposure to different sounds and different sound levels. Numerous studies have employed the revealed preference method on housing markets; their results and nuances are reviewed in more detail elsewhere (Nelson, 2008). The overwhelming majority of previous studies have focused on noise from airports, high-traffic roads and to a lesser extent, railways. A meta-analysis of 40 revealed preference studies of housing markets which included a metric for airport noise found the price of residential properties declined by between $0.50 \%$ and $0.70 \%$ per $\mathrm{dB}(\mathrm{A})$ (Nelson, 2004). Similar meta-analyses of revealed preference studies focused on traffic noise have found comparable detrimental effects on housing prices. Nelson (1982) reviewed nine empirical studies covering 14 different housing markets in North American and found properties declined in value by an average of $0.40 \%$ per $\mathrm{dB}(\mathrm{A})$. A more recent meta-analysis comparing 16 estimates from nine different revealed preference studies determined residential property values declined by an average of $0.64 \%$ per $\mathrm{dB}(\mathrm{A})$ (Bertrand, 1997).

While revealed preference methods offer a large degree of validity, they are poorly suited to examine the feasibility or social 
acceptability of different policy solutions. As a result, economists have increasingly utilized stated preference methods to value sound. In stated preference studies, the researcher constructs a simulated market for an environmental resource. Research subjects, who are often random samples of the general public, are then solicited to state their willingness to pay for that resource. Experimental manipulation, such as removing certain sounds or altering amplitude levels, allows the analyst a high degree of flexibility in attaining willingness to pay values. Additionally, the researcher has explicit control over the payment mechanism, such as altering existing tax rates or creating a hypothetical market of tradable noise pollution permits (Carson and Hanemann, 2005). Relative to revealed preference methods utilizing market transaction data, stated preference studies allow the analyst to isolate the monetary values ascribed to anthropogenic noise; imperfections in real markets are avoided. Navrud (2002), in his review of studies using stated preference methods to value sound, concludes the primary benefit of stated preference studies is their ability to explore non-existent sound management policies.

\subsubsection{Current and future research needs}

The methodological capabilities that economists can bring to bear on soundscape research are potentially very powerful. Revealed preference methodologies enable economists to unbundle real market transactions and parse out the costs associated with unwanted sounds. Currently, the frontier of this research entails leveraging the capabilities of geographic information systems and the additional nuanced parameters they can generate to develop more spatially explicit and empirically robust valuation estimates (e.g., Salvi, 2007; Theebe, 2004; Cohen and Coughlin, 2008). The utilization of geographic information systems in econometric modeling has enabled a better accounting of the spatial heterogeneity that has proved problematic for revealed preference studies in the past. Nelson (2008) provides a thorough review of current and future research that is beyond the scope of this paper.

It is evident, based upon a large number of empirical studies, that the presence and amplitude of anthropogenic noise negatively affects housing values (and consequently tax revenues and the ability to provide public services). Interestingly, a recent revealed preference study of housing market transactions also showed home sales prices were higher in neighborhoods with higher levels of biological diversity in local bird populations (Farmer et al., 2013). What remains to be examined is whether or not anthropogenic noises have a compound detrimental effect on real estate markets by impacting the presence of wildlife populations. Future studies utilizing housing price data, average sound pressure (exposure) levels and wildlife population data would provide unique insights into how human systems (real estate markets) and natural systems (bird species diversity) are simultaneously impacted by the characteristics of their soundscapes. Even further insight could be gained if investigators were capable of disaggregating sound pressure (exposure) measurements by sound source. If this were possible, the investigators could estimate marginal willingness to pay (avoid) anthropogenic, biological and geophysical sounds.

Research on the economic dimensions of soundscapes can also be advanced through an expanded use of stated preference methodologies (choice experiments, contingent valuation and conjoint analyses) given their advantages in exploring the social acceptability of potential policy and management mechanisms. Two needs are paramount: First, a concentrated effort is needed to explore alternative and hypothetical soundscape management policies. Past studies using the stated preference method to value sound have not always placed a strong emphasis on shaping policy, focusing instead on deriving valid willingness to pay estimates. An example of this is asking individuals to value hypothetical houses which vary in their exposure to unwanted sounds (Arsenio et al., 2006; Wardman and Bristow, 2004). A variety of payment mechanisms for the policies described latter in this paper need to be explored. In built and more natural environments, multiple options such as variable property tax rates and the issuance of public bonds warrant exploration. Similarly, in terms of industrial noise polluters, stated preference methods could be used to explore the possibility of financing noise mitigation via tradable permit systems. Without a clear and empirically grounded understanding of how different soundscape management policies can be financed, there is little hope for either implementing or sustaining them.

A second frontier for stated preference research is to move beyond traditional data collection methodologies, which are almost solely mail- or web-based surveys and questionnaires. This method of data collection requires stated preference studies to value hypothetical percentage reductions in noise levels (e.g., a $50 \%$ reduction in current levels). It is unknown whether respondents can accurately estimate how a sound differs when it is experienced at $60 \mathrm{~dB}(\mathrm{~A})$ as opposed to $30 \mathrm{~dB}(\mathrm{~A})$ (Baranzini et al., 2010a,b). Ongoing advances in this area involve conducting stated preference experiments in a laboratory setting equipped with virtual immersion systems. The use of immersive virtual environments enables the researcher to have full control over a manipulated environmental setting which holds the potential to yield more valid willingness-to-pay estimates (Loomis and Blascovich, 1999). Leveraging these new capabilities will also allow researchers to parse out explicit values for individual noise sources. Navrud (2002) notes one of the main limitations for the stated preference method's ability to inform policy is the inability to know exactly what sounds individuals consider (e.g., traffic, human communication, sirens, etc.) when responding to a mail- or web-based survey. The use of immersive virtual environments solves this problem by allowing direct experimental control over the source, amplitude and duration of exposure to individual sounds (Durlach and Mavor, 1994).

\subsection{Anthropology}

Thus far, we have outlined the various ways in which sound feeds back to human systems and directly influences individuals through a variety of psychological and behavioral processes. The influence of sound on individuals consequently shapes human systems at larger social scales such as social interactions, community organization and development and even the creation of cultural or place-based identities (Fig. 1, Label 6). Sound influences the human system across its coupled social scales.

At the broadest social scale, that of whole civilizations, anthropologists have been most adept at engaging and understanding the role of soundscapes in societal development. Culturally specific sounds such as tonal patterns in language and distinct musical styles shape cultural development in numerous complex ways such as enabling the creation of distinct identities and meanings. However, only relatively recently have anthropologists begun to examine how the acoustic characteristics of language, music and song are shaped by the biological or geophysical sounds found in a culture's local environment and subsequently utilized to create culturally distinct meanings and identities (Feld and Brennies, 2004; Samuels et al., 2010). The first notable exploration of a distinct cultural soundscape came from Turnbull (1961) and Turnbull and colleagues' study of the Mbutu pygmies who live in the Congo's Ituri rainforest $(1961 ; 1992)$ which was followed shortly by Feld's expansive study of the Kaluli, a non-literate clan living in the rain forests of Papua New Guinea (Feld, 1991, 1990). These early studies were both, uncoincidentally, focused on cultures living within rainforests, where sound travels 
farther than one can see, consequently resulting in social patterns of communication being more auditory. Similar subsequent studies have continued to document distinct cultural soundscapes, including language, song and music, across a wider variety of societies (Basso, 1985; Feld, 2000, 1996; Roseman, 1991; Seeger, 1987). These early acoustic ethnographies have subsequently inspired more contemporary work focused on the cultural meanings of soundscapes found in larger Western civilizations. This research has predominantly focused on detailing how globalization has resulted in a loss of local identities and culture-specific ways of interacting with and shaping our soundscapes (Bennett and Peterson, 2004; Hansen, 2006; Hirschkind, 2006; Sakakeeny, 2010; Seeger, 2003; Wallach, 2008; White, 2008). In a time of rapid social, economic and ecological change at a global scale, there is a need for further research to document and critically examine the role that sound plays in shaping distinct cultural identities and societal meanings.

\section{Soundscape policy and management}

\subsection{Existing soundscape policy and management}

The characteristics defining the composition of soundscapes are directly and indirectly driven by public policies (Fig. 1, Label 7). Most public policies to date have been focused on mitigating specific sources of noise (almost exclusively transportation infrastructure) and have attempted to establish anthropocentric amplitude thresholds for built urban environments. Within the United States for example, the Occupational Safety and Health Act (1970), the Noise Control Act (1972) and the Quiet Communities Act (1978) are all legislative acts establishing sound pressure level thresholds. For example, the US Department of Housing and Urban Development used these laws to mandate new construction not result in daytime sound pressure levels above $75 \mathrm{~dB}$ (US Department of Housing and Urban Development, 1979). However, both the Occupational Safety and Health Act and the Noise Control Act receive little, if any, congressional appropriations. Similar federal or intergovernmental guidelines have also been established outside the United States as well. The Swiss government adopted the Federal Ordinance on Noise Protection in 1987, which requires noise mitigation on public roads (OFEFP, 2002). Similar to US policies, many of the mitigation measures required under the Swiss ordinance are not initiated or completed due to a lack of federal appropriations to cover their costs (OFS and OFEFP, 1997). The first and most notable intergovernmental guidelines were created in the late 1990s when the World Health Organization issued recommendations for desirable noise levels in built environments (Berglund et al., 1999; WHO Regional Office for Europe, 2009). Shortly thereafter, the European Union adopted standards for the monitoring of outdoor noise in urban areas (2002). The EU policy, commonly known as the Environmental Noise Directive, requires large European cities develop urban noise maps. City governments are tasked with using the maps to establish noise action plans that include long-term monitoring protocols. Collectively, existing public policies suffer from being highly focused on individual noise sources and being poorly incorporated into other environmental and urban planning frameworks.

\subsection{Shifting from source-focused policies to spatially defined policies}

A larger concerted effort is needed at local, regional, federal and international levels to refocus noise abatement policies away from monitoring and managing specific noise sources to monitoring and managing soundscapes across large geographic spaces such as metropolitan areas and urban centers. The purpose of this shift is to expand the geographic scope of existing regulatory capabilities. While the human health impacts of noise are well documented, existing policies are only capable of mitigating impacts in areas prone to high noise levels such as airports, construction sites and highways. These areas only comprise a fraction of the built landscape (Seto et al., 2007). If monitoring and management protocols were inclusive of entire population centers, the potential to identify and manage undesirable soundscapes would be greatly expanded. Future polices should aim to improve human health by providing and maintaining non-detrimental soundscapes. Protocols for acoustic monitoring across urban regions are already being implemented in large European cities as required by the EU's Environmental Noise Directive. Some European cities, such as Dublin, Ireland, have mapped noise across their metropolitan region, developing acoustic action plans and have reflected on challenges faced throughout the process so that other cities can be more efficient in their mapping and planning processes (King et al., 2011; Murphy and King, 2011, 2010; Murphy et al., 2009). Policies similar to the Environmental Noise Directive, where regulatory capacities are enabled across large geographic spaces and not targeted at specific noise sources, are needed in other regions of the world. Progressive cities in developed countries with established, yet flagging, noise mitigation policies might be most receptive to more holistic sound management policies (Moudon, 2009). Local and regional governance structures would be well served to learn from and potentially build-upon the Environmental Noise Directive's process of proactive acoustic monitoring; best practice manuals are currently available (see European Commission Working Group Assessment of Exposure to Noise 2006). In addition to shifting existing policy from source management to whole soundscape management, another fruitful avenue for soundscape policy is to integrate sound management into existing environmental and urban planning frameworks.

\subsection{Integration into other environmental and urban planning frameworks}

There has been little effort among landscape and urban planners to incorporate soundscape quality into existing environmental and urban planning frameworks despite numerous avenues where integration can occur (Weber, 2013). Within the United States, for example, all federal projects and authorizations are required under the National Environmental Policy Act of 1970 (NEPA) to be evaluated for their potential environmental and socio-economic impacts. Determining the extent of the affected environment is left to the federal regulatory agency with statutory responsibilities over the planning process. Most often, clearly delineating the affected environment is relatively simple. For example, the activities involved in a stream restoration project are delimited by the stream and its riparian buffer areas. The responsible agency has relatively little trouble in identifying potential impacts within the affected environment. For projects that have the potential to impact soundscape quality however, quantifying impacts can be extremely difficult. Estimating potential impacts requires access to, and familiarity with, accepted sound-propagation models (e.g., the Federal Highway Administration Traffic Noise Model). Most resource planners are not aware of sound propagation models and how they can be utilized to estimate impacts to natural and human systems. Consequently, soundscape impacts are frequently not considered in NEPA required evaluations (Wisdom, 2007). Environmental Impact Assessments are required across Europe as well (The Commission to the European Parliament and Council, 2011).

Environmental policy formulation and legitimization across both the United States and Europe suffer from being driven by a 
need to document obvert negative impacts to the health of natural and human systems (Braybrooke and Lindblom, 1963). Very little policy is crafted and implemented out of a desire to improve human quality of life or ecosystem health. Some resource management agencies however, are beginning to make notable policy changes motivated primarily by a desire to improve soundscape quality as opposed to the need to avoid socially undesirable effects on natural and human systems.

The leading resource management agency in this regard is the US National Park Service, which explicitly calls for an evaluation of soundscape impacts when they are delineating a project's potential affected environment (National Park Service, 2001). The National Park Service also requires all park units with actual or proposed commercial air tour operations to develop an "Air Tour Management Plan" to mitigate the impacts of air tour operations on wildlife and visitor experiences. Federal agencies in the US such as the National Oceanic and Atmospheric Administration and the Fish and Wildlife Service, which must adhere to the NEPA planning process in their consideration of impacts to freshwater and marine resources, have also begun to more explicitly consider impacts to natural soundscapes (Richardson et al., 1995). Another avenue that has been suggested is the incorporation of soundscape impacts into projects requiring life cycle assessments, a technique designed to gauge the environmental and socio-economic impacts of a project over its entire lifespan (Cucurachi et al., 2012). Collectively the incorporation of soundscape impacts into federal planning processes, such as the preparation of environmental impact statements or life cycle assessments, remains inconsistent across agencies and even within agencies (Wisdom, 2007). More consistent evaluations of soundscape impacts will be needed as the science of soundscape ecology continues to grow and as the value of natural soundscapes becomes more prominent in the public consciousness.

Aside from federal processes, there is also an opportunity and need to incorporate soundscapes more directly into city, urban and landscape level planning efforts (Adams et al., 2006). Most current planning efforts at these scales rely heavily on managing visual esthetics, with little attention given to managing acoustic characteristics. One possible reason for this is the ease of conveying visual imagery through modified maps, illustrations or renderings. Relative to esthetic impacts, it is much more difficult to capture and convey what a future urban space or landscape will sound like. The majority of current planning guidelines in developed countries are spatially explicit, meaning they have planning and zoning regulations which segregate urban space relative to appropriate industrial uses or residential population densities. Spatially explicit planning guidelines can easily be augmented to include regulations for socially desirable soundscapes within urban areas. Just as a metropolitan area is sub-divided by planning commissions in efforts to control where and to what extent development occurs, delineations could be made for establishing and maintaining desirable soundscapes in certain locations. The development of urban noise maps and their subsequent action plans under the Environmental Noise Directive in Europe, offer the most promising opportunity for this coupling of existing spatial planning regulations with new soundscape regulations. New soundscape policies need not be created from whole cloth. Rather, progressive city and landscape planners should seek out existing policies, guidelines and regulations that could benefit their areas through additional attention to acoustic characteristics.

\section{New frontiers in soundscape ecology: human and policy dimensions}

The field of soundscape ecology can benefit from science that approaches soundscapes as a product of coupled natural and human systems (Pijanowski et al., 2011a). The burgeoning field has been actively attempting to better understand how the acoustic characteristics and dynamics are related to the structure and functioning of natural systems. Ongoing work is focused on a variety of areas such as attempting to understand the spatial and temporal dynamics of sound across different scales and developing a better understanding of the impact of soundscapes on wildlife (Pijanowski et al., 2011b). Soundscape research focused wholly within natural systems is vitally important. But in isolation, it will not lead to sustainable management practices. Concomitant and concentrated research efforts from the psychological, social, behavioral, economic and policy sciences are also needed to understand how human systems shape soundscapes and consequently how the characteristics of those soundscapes feedback into and affect human systems.

To date there has been considerable research on the human and policy dimensions of soundscapes. However, this previous research has been scattered across a wide variety of disparate fields, each working with its own purposes and objectives. One objective of this review article has been to provide a conceptual framework for the human and policy dimensions of soundscapes. The human and policy dimensions of soundscape ecology framework models how sound traverses various dimensions within human systems, eventually leading to individual and collective behaviors that drive the acoustic composition of built and natural environments. The framework, being the product of systems-oriented thinking, can serve as a unifying model around which diverse disciplines can situate their work and see how it integrates and complements research from other fields. The intent is to extend the frontiers within and across disciplinary boundaries by plotting out current trajectories and intersecting points of focus. Through our review of how soundscapes feedback to individual and public health, psychological well-being, economic systems and cultural identities, we have mapped out several of these disciplinary frontiers. Undoubtedly there are a variety of others outside our expertise that could yield additional insights into human responses to soundscapes.

If engaged through rigorous empirical inquiry, these frontiers will ultimately lead to a better understanding of the role that soundscapes play in a time of abrupt and unprecedented environmental change. There is growing concern that the availability of 'natural' soundscapes is dwindling (Dumyahn and Pijanowski, 2011b; Krause, 1987; Schafer, 1994). Increases in technology and the spatial expansion of human populations over the past century have radically expanded the presence and magnitude of anthropogenic sounds in natural landscapes' acoustic compositions. As a result, the long-term sustainability of stable processes within both natural and human systems is threatened. In natural systems, for example, the bioacoustic changes in response to anthropogenic noise have been shown to be a form of maladaptation across a wide variety of species. The sexual signals of amphibians (Barber et al., 2010), birds (Slabbekoorn and Ripmeester, 2008) and marine mammals (Richardson et al., 1995) have all been impacted, resulting in lower breeding success and population growth rates. The negative feedback loops caused by increased anthropogenic noise can also be traced through human systems as well, as the feedbacks outlined in this paper illustrate. In short, as the acoustic characteristics of a landscape change, biological and human systems can be stressed; these stresses are negative feedbacks that ultimately threaten the stability and sustainability of existing processes within natural and human systems.

The solution, we suggest, must come from more proactive, integrative and holistic policies at a variety of scales from local planning guidelines to intergovernmental agreements and regulations. Specifically, we have offered two potential avenues for future soundscape policies and planning processes to explore. The first 
involves shifting from source-focused policies to spatially defined policies. Current policies that focus on well-known noise pollution sources such as airports and railways are not sufficient to fully account for the negative impacts accruing within human communities as a result of increases in unwanted noise exposures. Future soundscape management policies are likely to gain much more traction through a full accounting of negative impacts to individual and community health. The second policy suggestion we offered was for proactive city planners and environmental managers to seek out ways to leverage existing policies and guidelines as potential vehicles for soundscape management. Within the United States, increased consideration of soundscape impacts in environmental assessments and environmental impact statements is needed. Internationally, and at local and regional levels of government, spatially explicit planning frameworks such as zoning offer initial and potentially fruitful points of exploration. Successful soundscape policy will likely require decision makers to explore novel pathways to development and implementation.

In conclusion, the presence of and ability to experience natural soundscapes is dwindling worldwide as a result of increased urbanization in developed countries and increased levels of industrialization in the developing world. The most successful policy solutions are likely to come from integrated solutions informed by both the natural and social sciences. The human and policy dimensions of soundscape ecology framework provides a unifying model around which various allied social scientists can situate their research. Collectively, this will lead to a more holistic understanding of how human systems are impacted by, and simultaneously shape, their soundscapes.

\section{Acknowledgements}

The authors would like to acknowledge Dr. Roger L. Moore, Dr. Jonathan Beever, and Tian Guo for their comments and suggestions on previous versions of the paper.

\section{References}

Adams, M., Cox, T., Moore, G., Croxford, B., Refaee, M., Sharples, S., 2006. Sustainable soundscapes: noise policy and the urban experience. Urban Stud. 43, 23852398, http://dx.doi.org/10.1080/00420980600972504.

Appleton, J., 1975. The Experience of Landscape. Wiley, New York.

Arsenio, E., Bristow, A.L., Wardman, M., 2006. Stated choice valuations of traffic related noise. Transp. Res. D: Transp. Environ. 11, 15-31, http://dx.doi.org/ 10.1016/j.trd.2005.07.001.

Axelsson, O., Nilsson, M.E., Berglund, B., 2010. A principal components model of soundscape perception. J. Acoust. Soc. Am. 128, 2836-2846.

Babisch, W., 2008. Road traffic noise and cardiovascular risk. Noise Health 10, $27-$ 33, http://dx.doi.org/10.4103/1463-1741.39005.

Balling, J.D., Falk, J.H., 1982. Development of visual preferences for natural landscapes. Environ. Behav. 14, 5-28.

Baranzini, A., Schaerer, C., Ramirez, J.V., Thalmann, P., 2010a. Feel it or measure it perceived vs. measured noise in hedonic models. Transp. Res. D: Transp. Environ. 15D, 473-482.

Baranzini, A., Schaerer, C., Thalmann, P., 2010b. Using measured instead of perceived noise in hedonic models. Transp. Res. D: Transp. Environ. 15, 473-482, http://dx.doi.org/10.1016/j.trd.2010.06.002.

Barber, J.R., Crooks, K.R., Fristrup, K.M., 2010. The costs of chronic noise exposure for terrestrial organisms. Trends Ecol. Evol. 25, 180-189, http://dx.doi.org/ 10.1016/j.tree.2009.08.002.

Basso, E.B., 1985. A Musical View of the Universe: Kalapalo Myth and Ritual Performances. University of Pennsylvania Press, Philadelphia, PA.

Bennett, A., Peterson, R.A. (Eds.), 2004. Music Scenes: Local, Translocal, and Virtual. Vanderbilt University Press, Nashville, TN.

Berglund, B., Eriksen, C.A., Nilsson, M.E., 2001. Perceptual characterization of soundscapes in residential areas. In: Alippi, A. (Ed.), International Congress on Acoustics 2001. International Commission for Acoustics, Rome, Italy, pp. 284-285.

Berglund, B., Lindvall, T., Schwela, D.H., 1999. Guidelines for community noise.

Berglund, B., Nilsson, M.E., 2006. On a tool for measuring soundscape quality in urban residential areas. Acta Acust. United Acust. 92, 938-944.

Bertrand, N.F., 1997. Meta-analysis of studies of willingness to pay to reduce traffic noise. (M.Sc. dissertation)University College, London.

Bjork, E.A., 1985. The perceived quality of natural sounds. Acustica 57, 185-188.
Blackmore, S., 2000. The Meme Machine. Oxford University Press, Oxford, UK. Bradley, M.M., Lang, P.J., 2000. Affective reactions to acoustic stimuli. Psychophysiology 37, 204-215.

Braybrooke, D., Lindblom, C., 1963. A Strategy of Decision. Free Press of Glencoe, New York.

Breakwell, G.M., 1992. Social Psychology of Identity and the Self Concept. Surrey University Press, Guilford, Surrey, UK.

Brown, A.L., Kang, J., Gjestland, T., 2011. Towards standardization in soundscape preference assessment. Appl. Acoust. 72, 387-392, http://dx.doi.org/10.1016/ j.apacoust.2011.01.001.

Bruner, G.C., 1990. Music, mood and marketing. J. Market. 54, 94-104.

Bunt, L., Hoskyns, S., 2002. The Handbook Of Music Therapy. Routledge, New York. Burns, W., 1973. Noise and Man. John Murray, London.

Burt, J.L., Bartolome, D.S., Burdette, D.W., Comstock, J.R., 1995. A psychological evaluation of the perceived urgency of auditory warning signals. Ergonomics 38, 2327-2340.

Cain, R., Jennings, P., Poxon, J., 2013. The development and application of the emotional dimensions of a soundscape. Appl. Acoust. 74, 232-239, http:// dx.doi.org/10.1016/j.apacoust.2011.11.006.

Carson, R.T., Hanemann, W.M., 2005. Contingent valuation. In: Maler, K.-G., Vincent, J.R. (Eds.), Handbook of Environmental Economics. Elsevier, Amsterdam, pp. 821-936.

Cheung, S.N.S., 1987. Common property rights. In: Eatwell, J., Milgate, J., Newman, P. (Eds.), The New Palgrave: A Dictionary of Economics. Macmillan, London, pp. 504-505

Cohen, A.J., 2001. Music as a source of emotion in film. In: Juslin, P.N., Slodoba, J.A. (Eds.), Music and Emotion: Theory and Research. Oxford University Press, Oxford, United Kingdom, pp. 249-272.

Cohen, J.P., Coughlin, C.C., 2008. Spatial hedonic models of airport noise, proximity, and housing prices. J. Reg. Sci. 48, 859-878, http://dx.doi.org/10.1111/j. 14679787.2008.00569.x.

Cucurachi, S., Heijungs, R., Ohlau, K., 2012. Towards a general framework for including noise impacts in LCA. Int. J. Life Cycle Assess. 17, 471-487, http:// dx.doi.org/10.1007/s11367-011-0377-4.

Davenport, M.A., Anderson, D.H., 2005. Getting from sense of place to place-based management: an interpretive investigation of place meanings and perceptions of landscape change. Soc. Nat. Resour. 18, 625-641, http://dx.doi.org/10.1080/ 08941920590959613.

De Coensel, B., Botteldooren, D., 2006. The quiet rural soundscape and how to characterize it. Acta Acust. United Acust. 92, 887-897.

Dubois, D., Gustavino, C., Raimbault, M., 2006. A cognitive approach to urban soundscapes: using verbal data to access everyday life auditory categories. Acta Acust. United Acust. 92, 865-874.

Dumyahn, S., Pijanowski, B.C., 2011a. Beyond noise mitigation: managing soundscapes as common-pool resources. Landsc. Ecol. 26, 1311-1326, http://dx.doi.org/ 10.1007/s10980-011-9637-8.

Dumyahn, S., Pijanowski, B.C., 2011b. Soundscape conservation. Landsc. Ecol. 26 1327-1344, http://dx.doi.org/10.1007/s10980-011-9635-x.

Durlach, N.I., Mavor, A.S., 1994. Virtual Reality: Scientific and Technological Challenges. National Academies Press, Washington, DC.

European Commission Working Group Assessment of Exposure to Noise, 2006 Good practice guide for strategic noise mapping and the production of associated data on noise exposure (No. WG-AEN 016) .

European Union, 2002. Directive 2002/49/EC relating to the assessment and management of environmental noise. Off. J. Eur. Commun. L189

Falk, J.H., Balling, J.D., 2010. Evolutionary influence on human landscape preference Environ. Behav. 42, 479-493, http://dx.doi.org/10.1177/0013916509341244.

Farina, A., 2014a. Soundscape and landscape ecology. In: Soundscape Ecology: Principles, Patterns, Methods, and Applications. Springer, Dordrecht, The Netherlands, pp. 1-28.

Farina, A., 2014b. Human dimension of the soundscape: from individuals to society. In: Soundscape Ecology. Springer, The Netherlands, pp. 107-142.

Farmer, M.C., Wallace, M.C., Shiroya, M., 2013. Bird diversity indicates ecological value in urban home prices. Urban Ecosyst. 16, 131-144, http://dx.doi.org/ $10.1007 / \mathrm{s} 11252-011-0209-0$.

Feld, S., 1990. Sound and Sentiment: Birds, Weeping, Poetics, and Song in Kaluli Expression. University of Pennsylvania Press, Philadelphia, PA.

Feld, S., 1991. Voices of the rainforest: politics of music. Public Cult. 4, 131-140.

Feld, S., 1996. Pygmy pop, a genealogy of schizophonic mimesis. Yearb. Tradit Music 28, 1-35.

Feld, S., 2000. A sweet lullaby for world music. Public Cult. 12, 145-171.

Feld, S., Brennies, D., 2004. Doing anthropology in sound. Am. Ethnol. 41, 461-474.

Ferguson, T.J., Berlin, G.L., Kuwanwisiwma, L.J., 2009. Kukhepya: searching for Hopi trails. In: Snead, J.E., Erickson, C.L., Darling, A.J. (Eds.), Landscapes of Movement: The Anthropology of Paths, Trails, and Roads. University of Pennsylvania Museum of Archaeology and Anthropology, Philadelphia, PA, pp. 20-41.

Fletcher, N.H., 2007. Animal bioacoustics. In: Rossing, T.D. (Ed.), Handbook of Acoustics. Springer, New York, pp. 785-802.

Gabrielsson, A., Sjögren, H., 1979. Perceived sound quality of sound reproducing systems. J. Acoust. Soc. Am. 65, 1019-1033.

García-Llorente, M., Martín-López, B., Iniesta-Arandia, I., López-Santiago, C.A., Aguilera, P.A., Montes, C., 2012. The role of multi-functionality in social preferences toward semi-arid rural landscapes: an ecosystem service approach. Environ. Sci. Policy 19/20, 136-146, http://dx.doi.org/10.1016/ j.envsci.2012.01.006. 
Guastavino, C., Katz, B.F.G., 2004. Perceptual evaluation of multi-dimensional spatial audio reproduction. J. Acoust. Soc. Am. 116, 1105-1115, http:/ dx.doi.org/10.1121/1.1763973.

Gustavino, C., 2006. The ideal urban soundscape: investigating the sound quality of French cities. Acta Acust. United Acust. 92, 945-951.

Hansen, T.B., 2006. Sounds of freedom: music, taxis, and racial imagination in South Africa. Public Cult. 18, 185-208.

Hirschkind, C., 2006. The Ethical Soundscape: Cassette Sermons and Islamic Counterpublics, Columbia University Press, New York.

Hvenegaard, G.T., 2002. Birder specialization differences in conservation involvement, demographics, and motivations. Hum. Dimens. Wildl. 7, 21-36, http:// dx.doi.org/10.1080/108712002753574765.

International Standards Organization, 2013. Acoustics - Soundscape - Part 1: Definition and Conceptual Framework (International Standard No. ISO/FDIS 12913-1) International Standards Organization.

Ittelson, W.H., Franck, K.A., O'Hanlon, T.J., 1976. The nature of environmental experience. In: Wapner, S., Cohen, S., Kaplan, B. (Eds.), Experiencing the Environment. Plenum, New York, pp. 187-206.

Jennings, P., Cain, R., 2013. A framework for improving urban soundscapes. Appl. Acoust. 74, 293-299.

Jorgensen, B.S., Stedman, R.C., 2001. Sense of place as an attitude: lakeshore owners attitude toward their properties. J. Environ. Psychol. 21, 233-248.

Juslin, P.N., Slodoba, J.A. (Eds.), 2001. Music and Emotion: Theory and Research. Oxford University Press, Oxford, United Kingdom.

Juslin, P.N., Västfjäll, D., 2008. Emotional responses to music: the need to consider underlying mechanisms. Behav. Brain Sci. 31, 559-621.

Kaplan, R., Kaplan, S., 1989. Experience and Nature: A Psychological Perspective. Cambridge University Press, New York.

Kaplan, S., 1992. Environmental preference in a knowledge-seeking knowledgeusing organism. In: Barkow, J.H., Cosmides, L., Tooby, J. (Eds.), The Adapted Mind: Evolutionary Psychology and the Generation of Culture. Oxford University Press, New York, pp. 581-600

Kawai, K., Kojima, T., Hirate, K., Yakuoka, M., 2004. Personal evaluation structure of environmental sounds: experiments of subjective evaluation using subjects own terms. J. Sound Vib. 277, 523-533.

Kerrick, J.S., Nagel, D.C., Bennet, R.L., 1969. Multiple ratings of sound stimuli. J Acoust. Soc. Am. 45, 1014-1017.

King, E.A., Murphy, E., Rice, H.J., 2011. Implementation of the EU environmental noise directive: lessons from the first phase of strategic noise mapping and action planning in Ireland. J. Environ. Manage. 92, 756-764, http://dx.doi.org 10.1016/j.jenvman.2010.10.034.

Krause, B., 1987. Bioacoustics, habitat ambience in ecological balance. Whole Earth Rev. 57, 14-18.

Kryter, K.D. 1985. The Effects of Noise on Man. Academic Press, London.

Kuehne, L.M., Padgham, B.L., Olden, J.D., 2013. The soundscapes of lakes across an urbanization gradient. PLoS ONE 8, e55661, http://dx.doi.org/10.1371/journal. pone.0055661.

Laiolo, P., 2010. The emerging significance of bioacoustics in animal species conservation. Biol. Conserv. 143, 1635-1645, http://dx.doi.org/10.1016/j.biocon.2010.03.025.

Lewis, J.W., Talkington, W.J., Tallaksen, K.C., Frum, C.A., 2012. Auditory object salience: human cortical processing of non-biological action sounds and their acoustic signal attributes. Front. Syst. Neurosci. 6, http://dx.doi.org/10.3389/ fnsys.2012.00027.

Litovsky, R.Y., 2012. Development of binaural and spatial hearing. In: Werner, L.A., Fay, R.R., Popper, A.N. (Eds.), Human Auditory Development. Springer, New York, pp. 163-195.

Liu, J., Dietz, T., Carpenter, S.R., Folke, C., Alberti, M., Redman, C.L., Schneider, S.H. Ostrom, E., Pell, A.N., Lubchenco, J., Taylor, W.W., Ouyang, Z., Deadman, P., Kratz, T., Provencher, W., 2007. Coupled human and natural systems. AMBIO 36, 639649, http://dx.doi.org/10.1579/0044-7447(2007)36[639:CHANS]2.0.CO;2.

Loomis, J.M., Blascovich, J.J., 1999. Immersive virtual environment technology as a basic research tool in psychology. Behav. Res. Methods Instrum. Comput. 31, $557-564$

McEwen, B.S., 2000. Allostasis and allostatic load. In: Fink, G. (Ed.), Encyclopedia of Stress. Academic Press, London, England, pp. 145-149.

McEwen, B.S., Seeman, T., 1999. Protective and damaging effects of mediators of stress: elaborating and testing the concepts of allostasis and allostatic load. Ann. N. Y. Acad. Sci. 896, 30-47.

Miedema, H.M., Oudshoorn, C.G., 2001. Annoyance from transportation noise: relationships with exposure metrics DNL and DENL and their confidence intervals. Environ. Health Perspect. 109, 409-416.

Miedema, H.M.E., 2007. Annoyance caused by environmental noise: elements for evidence-based noise policies. J. Soc. Issues 63, 41-57, http://dx.doi.org/ 10.1111/j. 1540-4560.2007.00495.x.

Ministry of Infrastructure and Environment, 2011. Response on Amendments Related to the Parliamentary Discussion on Swung Legislation (No. LOK2011.049311) Ministry of Infrastructure and Environment, Amsterdam, The Netherlands.

Morgan, P., 2010. Towards a developmental theory of place attachment. J. Environ. Psychol. 30, 11-22, http://dx.doi.org/10.1016/j.jenvp.2009.07.001.

Moudon, A.V., 2009. Real noise from the urban environment: how ambient community noise affects health and what can be done about it. Am. J. Prev. Med. 37 167-171, http://dx.doi.org/10.1016/j.amepre.2009.03.019.

Murphy, E., King, E.A., 2010. Strategic environmental noise mapping: methodological issues concerning the implementation of the EU Environmental Noise
Directive and their policy implications. Environ. Int. 36, 290-298, http:// dx.doi.org/10.1016/j.envint.2009.11.006.

Murphy, E., King, E.A., 2011. Scenario analysis and noise action planning: modelling the impact of mitigation measures on population exposure. Appl. Acoust. 72, 487-494, http://dx.doi.org/10.1016/j.apacoust.2010.10.006.

Murphy, E., King, E.A., Rice, H.J., 2009. Estimating human exposure to transport noise in central Dublin, Ireland. Environ. Int. 35, 298-302, http://dx.doi.org/ 10.1016/j.envint.2008.07.026.

Muzet, A., 2007. Environmental noise, sleep and health. Sleep Med. Rev. 11, 135142, http://dx.doi.org/10.1016/j.smrv.2006.09.001.

National Park Service, 2001. Director's Order 12 Handbook. National Park Service, Washington, DC

Navrud, S., 2002. The State-of-the-Art on Economic Valuation of Noise: Final Report to the European Commission. Agricultural University of Norway, Oslo, Norway.

Nelson, J.P., 1982. Highway noise and property values: a survey of recent evidence. J. Transp. Econ. Policy 16, 117-138.

Nelson, J.P., 2004. Meta-analysis of airport noise and hedonic property values. J. Transp. Econ. Policy 38, 1-27.

Nelson, J.P., 2008. Hedonic property value studies of transportation noise: aircraft and road traffic. In: Baranzini, A., Ramirez, J., Schaerer, C., Thalmann, P. (Eds.), Hedonic Methods in Housing Markets. Springer, New York, pp. 57-82.

Nilsson, M.E., 2007. A-weighted sound pressure level as an indicator of perceived loudness and annoyance of road-traffic sound. J. Sound Vib. 302, 197-207.

Nilsson, M.E., Berglund, B., 2006. Soundscape quality in suburban green areas and city parks. Acta Acust. United Acust. 92, 903-911.

OFEFP, 2002. Fiche d'information lutte contre le bruit. OFEFP, Berne, Switzerland.

OFS (Office Federal de la Statistique), OFEFP, 1997. L'environnement en Suisse, 1997. OFS and OFEFP, Berne, Switzerland.

Orians, G.H., 1980. Habitat selection: general theory and application to human behavior. In: Lockard, J.S. (Ed.), The Evolution of Human Social Behavior. Elsevier, Amsterdam, pp. 49-63.

Orians, G.H., Heerwagen, J.H., 1992. Evolved responses to landscapes. In: Barkow, J.H., Cosmides, L., Tooby, J. (Eds.), The Adapted Mind: Evolutionary Psychology and the Generation of Culture. Oxford University Press, New York, pp. 555-579.

Payne, S.R., Davies, W.J., Adams, M.D., 2009. Research into the practical policy applications of soundscape concepts and techniques in urban areas (No. NANR200) Department of Environment, Food, and Rural Affairs.

Pekin, B.K., Jung, J., Villanueva-Rivera, L.J., Pijanowski, B.C., Ahumada, J.A., 2012. Modeling acoustic diversity using soundscape recordings and LIDAR-derived metrics of vertical forest structure in a neotropical rainforest. Landsc. Ecol. 27, 1513-1522, http://dx.doi.org/10.1007/s10980-012-9806-4.

Pijanowski, B.C., Farina, A., Gage, S., Dumyahn, S., Krause, B., 2011a. What is soundscape ecology? An introduction and overview of an emerging new science. Landsc. Ecol. 26, 1213-1232, http://dx.doi.org/10.1007/s10980-011-9600-8.

Pijanowski, B.C., Villanueva-Rivera, L.J., Dumyahn, S.L., Farina, A., Krause, B.L., Napoletano, B.M., Gage, S.H., Pieretti, N., 2011b. Soundscape ecology: the science of sound in the landscape. BioScience 61, 203-216.

Proppe, D.S., Sturdy, C.B., St.Clair, C.C., 2013. Anthropogenic noise decreases urban songbird diversity and may contribute to homogenization. Glob. Change Biol. 19, 1075-1084, http://dx.doi.org/10.1111/gcb.12098.

Proshansky, H., Fabian, A., Kaminoff, R., 1983. Place-identity: physical world socialization of the self. J. Environ. Psychol. 3, 57-83, http://dx.doi.org/10.1016/ S0272-4944(83)80021-8.

Raimbault, M., Lavandier, C., Bérengier, M., 2003. Ambient sound assessment of urban environments: field studies in two French cities. Appl. Acoust. 64, 1241 1256, http://dx.doi.org/10.1016/S0003-682X(03)00061-6.

Richardson, W.J., Greene, C.R., Malme, C.I., Thomson, D.H., 1995. Marine Mammals and Noise. Academic Press, San Diego, CA

Richerson, P.J., Boyd, R., 2004. Not by Genes Alone: How Culture Transformed Human Evolution. University of Chicago Press, Chicago, IL.

Roseman, M., 1991. Healing Sounds from the Malaysian Rainforest: Temiar Music and Medicine. University of California Press, Berkeley, CA

Ruddell, E.J., Gramann, J.H., 1994. Goal orientation, norms, and noise-induced conflict among recreation area users. Leis. Sci. 16, 93-104, http://dx.doi.org/ $10.1080 / 01490409409513222$.

Russell, J.A., 2003. Core affect and the psychological construction of emotion. Psychol. Rev. 110, 145-172.

Ryden, K.C., 1993. Mapping the Invisible Landscape: Folklore, Writing, and the Sense of Place. University of Iowa Press, Ames, IA.

Sakakeeny, M., 2010. Under the bridge: an orientation to soundscapes in New Orleans. Ethnomusicology 54, 1-27.

Sallis, J.F., Floyd, M.F., Rodríguez, D.A., Saelens, B.E., 2012. Role of built environments in physical activity, obesity, and cardiovascular disease. Circulation 125, 729737, http://dx.doi.org/10.1161/CIRCULATIONAHA.110.969022.

Salvi, M., 2007. Spatial Estimation of the Impact of Airport Noise on Residential Housing Prices (SSRN Scholarly Paper No. ID 1000217) Social Science Research Network, Rochester, NY

Samuels, D.W., Meintjes, L., Ochoa, A.M., Porcello, T., 2010. Soundscapes: toward a sounded anthropology. Annu. Rev. Anthropol. 39, 329-345, http://dx.doi.org/ 10.1146/annurev-anthro-022510-132230.

Schafer, R.M., 1977. The Tuning of the World. Alfred A. Knopf, New York.

Schafer, R.M., 1994. The Soundscape: Our Sonic Environment and the Tuning of the World. Destiny Books, Rochester, VT.

Scott, D., Ditton, R.B., Stoll, J.R., Eubanks, T.L., 2005. Measuring specialization among birders: utility of a self-classification measure. Hum. Dimens. Wildl. 10, 53-74 http://dx.doi.org/10.1080/10871200590904888. 
Seeger, A., 1987. Why Saya Sing: A Musical Anthropology of an Amazonian People. Cambridge University Press, Cambridge, UK.

Seeger, A., 2003. Globalization from a local perspective in Brazil: the Suyá Indians and música sertaneja. In: Loza, S. (Ed.), Musical Cultures of Latin America, Global Effects, Past and Present. Selected Reports in Ethnomusicology. Ethnomusicology. University of California, Los Angeles, pp. 121-128.

Servick, K., 2014. Eavesdropping on ecosystems. Science 343, 834-837.

Seto, E.Y.W., Holt, A., Rivard, T., Bhatia, R., 2007. Spatial distribution of traffic induced noise exposures in a US city: an analytic tool for assessing the health impacts of urban planning decisions. Int. J. Health Geogr. 6, 1186-1211.

Sharp, D., 2010. Noisy days, noisy nights. J. Urban Health 87, 349-351, http:// dx.doi.org/10.1007/s11524-010-9440-x.

Slabbekoorn, H., Ripmeester, E.A.P., 2008. Birdsong and anthropogenic noise: implications and applications for conservation. Mol. Ecol. 17, 72-83, http:// dx.doi.org/10.1111/j.1365-294X.2007.03487.x.

Smith, J.W., Davenport, M.A., Anderson, D.H., Leahy, J.E., 2011. Place meanings and desired management outcomes. Landsc. Urban Plan. 101, 359-370, http:// dx.doi.org/10.1016/j.landurbplan.2011.03.002.

Stansfeld, S.A., 1992. Noise, noise sensitivity and psychiatric disorder: epidemiological and psychophysiological studies. Psychol. Med. Monogr. Suppl. 22S, 1-44.

Stansfeld, S.A., Berglund, B., Clark, C., Lopez-Barrio, I., Fischer, P., Öhrström, E., Haines, M.M., Head, J., Hygge, S., van Kamp, I., Berry, B.F., 2005. Aircraft and road traffic noise and children's cognition and health: a cross-national study. Lancet 365, 1942-1949, http://dx.doi.org/10.1016/S0140-6736(05)66660-3.

Stansfeld, S.A., Haines, M., Brown, B., 2000a. Noise and health in the urban environment. Rev. Environ. Health 15 , http://dx.doi.org/10.1515/ REVEH.2000.15.1-2.43.

Stansfeld, S.A., Haines, M., Burr, M., Berry, B., Lercher, P., 2000b. A review of environmental noise and mental health. Noise Health 2, 1-8.

Stansfeld, S.A., Matheson, M.P., 2003. Noise pollution: non-auditory effects on health. Br. Med. Bull. 68, 243-257, http://dx.doi.org/10.1093/bmb/ldg033.

Stern, P.C., 2000. Toward a coherent theory of environmentally significant behavior. J. Soc. Issues 56, 407-424

Stewart, W.P., 1992. Influence of the onsite experience on recreation experience judgments. J. Leis. Res. 24, 185-198.

Tempesta, T., 2010. The perception of agrarian historical landscapes: a study of the Veneto plain in Italy. Landsc. Urban Plan. 97, 258-272, http://dx.doi.org/ 10.1016/j.landurbplan.2010.06.010.

The Commission to the European Parliament and Council, 2011. On the Implementation of the Environmental Noise Directive in Accordance with Article 11 of Directive 2002/49/EC. European Commission, Brussels, Belgium.

Theebe, M.A.J., 2004. Planes, trains, and automobiles: the impact of traffic noise on house prices. J. Real Estate Finan. Econ. 28, 209-234, http://dx.doi.org/10.1023/ B:REAL.0000011154.92682.4b.

Truax, B., 1999. Handbook for Acoustic Ecology, 2nd ed. Cambridge Street Publishing, Cambridge, MA.
Tuan, Y.F., 1974. Topophilia: A Study of Environmental Perception, Attitudes, and Values. Prentice Hall, Englewood Cliffs, NJ.

Tucker, D., Gage, S.H., Williamson, I., Fuller, S., 2014. Linking ecological condition and the soundscape in fragmented Australian forests. Landsc. Ecol. 29, 745-758 http://dx.doi.org/10.1007/s10980-014-0015-1.

Turnbull, C.M., 1961. The Forest People. Simon \& Schuster, New York.

Turnbull, C.M., Chapman, F.S., 1992. Mbutu Pygmies of the Ituri Rainforest. Smithson Folkways CD 40401, Washington, DC.

Turner, B.L., Lambin, E.F., Reenberg, A., 2007. The emergence of land change science for global environmental change and sustainability. Proc. Natl. Acad. Sci. U. S. A. 104, 20666-20671, http://dx.doi.org/10.1073/pnas.0704119104.

US Department of Housing and Urban Development, 1979. Environmental criteria and standards, 24 CFR Part 51.

Van Kempen, E.E.M.M., Kruize, H., Boshuizen, H.C., Ameling, C.B., Staatsen, B.A.M., de Hollander, A.E.M., 2002. The association between noise exposure and blood pressure and ischemic heart disease: a meta-analysis. Environ. Health Perspect. 110, 307-317.

Västfjäll, D., Kleiner, M., Gärling, T., 2003. Affective reactions to interior aircraft sounds. Acta Acust. United Acust. 89, 693-701.

Viollon, S., Lavandier, C., 2000. Multidimensional assessment of the acoustic quality of urban environments. In: Cassereau, D. (Ed.), Inter Noise 2000. International Institute of Noise Control Engineering, Nice, France, pp. 2279-2284.

Wallach, J., 2008. Modern noise, fluid genres: popular music in Indonesia, 19972001. University of Wisconsin Press, Madison, WI.

Wallin, N., Merker, B., Brown, S., 2000. The Origins of Music. MIT Press, Cambridge, $\mathrm{MA}$.

Wardman, M., Bristow, A.L., 2004. Traffic related noise and air quality valuations: evidence from stated preference residential choice models. Transp. Res. D: Transp. Environ. 9, 1-27, http://dx.doi.org/10.1016/S1361-9209(03)00042-7.

Weber, M., 2013. Noise policy: sound policy? A meta level analysis and evaluation of noise policy in the Netherlands. (Doctoral dissertation)University of Utrecht, Utrecht, The Netherlands.

Werner, L.A., 2012. Overview and issues in human auditory development. In: Werner, L.A., Fay, R.R., Popper, A.N. (Eds.), Human Auditory Development. Springer, New York.

White, B.W., 2008. Rhumba Rules: The Politics of Dance Music in Mobutu's Zaire Duke University Press, Durham, NC.

WHO Regional Office for Europe, 2009. Night Noise Guidelines for Europe. World Health Organization, Copenhagen.

Wilson, E.O., 2004. On Human Nature. Harvard University, Cambridge, MA.

Wisdom, S., 2007. Role in science in assessing noise impacts on wildlife under National Environmental Policy Act (NEPA). J. Acoust. Soc. Am. 122 , http:// dx.doi.org/10.1121/1.2943008, 3082-3082.

World Health Organization, 2011. Burden of Disease from Environmental Noise: Quantification of Healthy Life Years Lost in Europe. World Health Organization, Regional Office for Europe, Copenhagen, Denmark. 